\title{
The basic pharmacoepidemiology of benzodiazepine use in Norway 2004-9
}

\author{
Jørgen G. Bramness ${ }^{1,2}$ and Joe A. Sexton ${ }^{3}$ \\ 1) Department of Pharmacoepidemiology, Norwegian Institute of Public Health, Oslo, Norway \\ 2) Norwegian Centre for Addiction Research, Institute of Clinical Medicine, University of Oslo, Norway \\ 3) Department of Biostatistics, Institute of Basic Medical Science, University of Oslo, Norway
}

Correspondence: Jørgen G. Bramness, Norwegian Centre for Addiction Research, University of Oslo, P.O. Box 1171 Blindern, 0318 Oslo

E-mail: j.g.bramness@medisin.uio.no Telephone:+47 23368977

\begin{abstract}
Objectives: Benzodiazepines are effective and safe drugs for treatment of insomnia, anxiety, epilepsy and muscle spasm, but there is also a potential for harmful use, abuse and addiction. Even though these drugs are used extensively, have been on the market for 50 years, and quite a few reports have been published on risk factors and patterns of use, the basic epidemiological parameters of use, such as incidence, prevalence, mean volume used and duration of use have not been documented in Norway. The aim of this study was to describe these basic pharmacoepidemiological parameters of benzodiazepine use.

Methods: Data were drawn from the Norwegian prescription database with an observation period of 5 years and 10 months between January 2004 and October 2009.

Results: Around 61 per 1000 Norwegians filled at least one prescription each year in the observation period. The annual incidence rate of new users was 15 per 1000 in 2007, falling to 12 per 1000 in 2009. Of the users of benzodiazepines $65 \%$ were female, and they used a lower mean volume than men did. The mean volume used was often very low and for the most part was quite stable. The average length of use was estimated to be between 9 and 15 years. In addition to fewer incident users, the mean volume used also seemed to be declining. Conclusion: Most benzodiazepine use in Norway lasted a short period or at a very low level. Some individuals, however, carried on using benzodiazepines for years.
\end{abstract}

This paper is based on a report from the Norwegian Institute of Public Health to the Norwegian Directorate of Health: Sexton JA, Bramness JG. "Bruken av benzodiazepiner i Norge 2004-9".

\section{INTRODUCTION}

Benzodiazepines have been on the market for more than 50 years and still have a wide range of uses. They are considered effective and safe drugs for the short term treatment of anxiety, insomnia, epilepsy and muscle spasms. They are also used for mild or deep sedation during different kinds of inventions, including surgery. They are considered safe because they have a wide therapeutic index; a wide range of different doses can be taken without the danger of intoxication as long as they are not taken together with other sedating drugs or by individuals with certain severe medical conditions. The benzodiazepines currently on the Norwegian market are listed in table 1 with their main use and dose range. In addition to the benzodiazepines currently marketed some additional ones are so called 'compassionately prescribed'. These include the sleeping drug triazolam $(0.15 \%$ of all benzodiazepine use $)$ and the anti anxiety drugs lorazepam, clobazam and bromazepam which account for $0.02 \%, 0.75 \%$ and $0.01 \%$ of the market respectively (www.reseptregisteret.no; accessed June $6^{\text {th }}$ 2011).

Even though benzodiazepines are considered safe and effective drugs, there are adverse effects. These include reduced psychomotor abilities, increasing impairment (1), increased risk of traffic accidents (2-4) and falls in the elderly due to sedation (5). The drugs may also impair cognitive abilities, and this can be especially negative among those elderly patients who already have more marginal cognitive function $(6,7)$. However, others have found the negative effects on cognitive function to be marginal $(8,9)$. Taken alone in high doses or, more usually, together with other intoxicants, benzodiazepines may also be abused. Injection opiate users use benzodiazepines to increase their high and dampen the withdrawal. Amphetamine users take the drugs to end binges of amphetamine use. If benzodiazepines are used on a regular basis, tolerance may develop over time leading to a decreased effect of the drug, or a need to increase the dose to achieve the same effect. Dependence may eventually develop, and this may not only include tolerance and withdrawal symptoms, but also craving. These adverse effects have led to concern about the use of benzodiazepines in the population (10) and we have regularly seen lo$\mathrm{cal}$, regional and national initiatives to reduce the use of benzodiazepines (11-14).

According to figures from the Norwegian Institute of Public Health more than 260000 Norwegians or approximately $6 \%$ of the population receive at least one prescription for a benzodiazepine each year (www. reseptregisteret.no; accessed June $6^{\text {th }}$ 2011). Even though we know about the adverse effects of benzo- 
Table 1. Benzodiazepines marketed in Norway, with main indication of use and most common dosing range.

\begin{tabular}{lccl}
\hline Drug & $\begin{array}{c}\text { Defined daily doses } \\
\text { (DDD) }\end{array}$ & $\begin{array}{c}\text { Equipotent to } \\
10 \mathrm{mg} \text { diazepam }\end{array}$ & Approved indication \\
\hline Diazepam & $10 \mathrm{mg}$ & $1 \mathrm{DDD}$ & Anxiety, muscle spasms, Epilepsy \\
Oxazepam & $50 \mathrm{mg}$ & $0,5-1 \mathrm{DDD}$ & Anxiety \\
Alprazolam & $1 \mathrm{mg}$ & $1 \mathrm{DDD}$ & Anxiety \\
Klonazepam & $8 \mathrm{mg}$ & $0,25 \mathrm{DDD}$ & Epilepsy \\
Nitrazepam & $5 \mathrm{mg}$ & $2 \mathrm{DDD}$ & Insomnia \\
Flunitrazepam & $1 \mathrm{mg}$ & $1 \mathrm{DDD}$ & Insomnia \\
Midazolam & $15 \mathrm{mg}$ & $1 \mathrm{DDD}$ & Injection benzodiazepine for starting anesthesia \\
\hline
\end{tabular}

diazepines, this figure alone cannot tell us if the use is too high or adequate. In fact, surprisingly little is known about the basic pharmacoepidemiology of benzodiazepines in Norway. Empirical knowledge gives us some facts. Use in the younger age groups (below 30 years of age) is quite uncommon and in these younger users, psychiatric conditions play a larger role (15). With increasing age, use becomes more common and most drugs are prescribed in general practice (16). Having a chronic condition and being on disability pension increases the likelihood of being prescribed benzodiazepines (17,18). Being female, older and using high doses increases the chances of becoming a long term user $(19,20)$. The strongest predictor of future use is prior use of benzodiazepines (5), but prior use of opioids also increases the chances of becoming a benzodiazepine user (21). Not surprisingly, receiving many prescriptions for benzodiazepines increases the chance of having inappropriate benzodiazepine use.

But still this knowledge is somewhat limited and the basic parameters of benzodiazepine use in Norway are largely unknown. The Norwegian Prescription Database (NorPD) gives full coverage of all prescriptions dispensed to Norwegian consumers outside of institutions since 2004. The aim of this study is to describe more closely the prevalence, incidence and volume and duration of use of benzodiazepines in Norway.

\section{MATERIALS AND METHODS}

\section{The Norwegian Prescription Database}

Data for this study were taken from the Norwegian prescription database (NorPD) at the Norwegian Institute of Public Health. NorPD covers all prescriptions dispensed to individuals outside institutions from January $1^{\text {st }} 2004$. All patients are registered with a pseudonym representing their Norwegian 11-digit person number, making it possible to follow a person anonymously over time. Approximately $2 \%$ of the prescriptions in NorPD were not registered with a valid 11-digit Norwegian person number. These were excluded from further analysis. Gender, year of birth and place of residence (county) were also registered. The prescribing physician was likewise registered with an identifier, gender, profession (medical doctor, dentist, veterinary etc.) and medical specialty (psychiatrist, surgeon, general practitioner etc.). The NorPD cannot be used in the control of individual patients or prescribers, but they can still be followed over time. All dispensed drugs are registered along with the strength of the drug, the amount and the date of dispensing. The reason for prescribing is not registered, but the code of reimbursement can sometimes be used as a proxy for diagnosis. Benzodiazepines are, however, not publicly reimbursed in Norway. Diagnosis will therefore not be possible in this report.

The data for this report were prescriptions for all benzodiazepines with marketing authorization in Norway (table 1) dispensed to individuals aged 18 years or older in the period January $1^{\text {st }} 2004$ till October $31^{\text {st }}$ 2009. In this investigation, drugs prescribed to patients in institutions or drugs given directly from the doctor's practice could not be traced to individuals and were therefore not included in the analysis. These constitute approximately $10 \%$ of the total amount of benzodiazepines prescribed.

\section{Pharmacoepidemiological measures}

In this pharmacoepidemiological study, we wanted to investigate the rate of benzodiazepine use, according to age and gender. We looked at the rate of users receiving at least one prescription during a year (12 month prevalence rate) and the rate of new users (incidence rate).

When estimating the incidence rate we needed to establish a wash-out period, to exclude patients who appeared for the first time but who were in fact previous users receiving their first prescription within the observation period. Earlier studies have used periods such as nine months $(22,23)$. This may be useful for other drugs, but drugs that are used intermittently for years may need a longer wash-out period before incidence rates can be observed.

Two other pharmacoepidemiological parameters of use were estimated on the basis of data from the NorPD.

For patients who filled more than one prescription for benzodiazepines, we calculated the mean volume used. This was calculated by dividing the total number of DDDs prescribed from the first to (but not including) the last recorded prescription by the number of days between the first and the last prescription. When 
Table 2. The rate (per 1000 persons) of incident users registered for the first time in the database during the observation period ${ }^{1}$.

\begin{tabular}{lrrrrrr}
\hline & \multicolumn{5}{c}{ Year } \\
\cline { 2 - 7 } & 2004 & 2005 & 2006 & 2007 & 2008 & $2009^{2}$ \\
\hline Users with only one prescription & 9.9 & 8.7 & 8.3 & 8.2 & 8.4 & 9.3 \\
Users with 2 prescriptions or more & 51.0 & 16.9 & 10.0 & 6.9 & 5.1 & 2.7 \\
Total & 60.9 & 25.6 & 18.3 & 15.1 & 13.5 & 12.0 \\
\hline
\end{tabular}

${ }^{1}$ The numbers correspond to the information given in figure 1.

${ }^{2}$ Based on figures up to October $31^{\text {st }}$ and adjusted to give the numbers predicting the whole of 2009 .

two prescriptions were filled on the same day, these were treated as one prescription, and the total of these two prescriptions was taken as the amount used until the next prescription was filled. We observed that the mean volume used was surprisingly stable and the vast majority of users did not vary their usage over time.

The time from the first prescription until the last for those receiving more than one prescription was defined as the duration of use. However, the real length of use could not be observed as a person could have had their first prescription before the observation period started and/or after the observation period ended. Thus, duration of use had to be estimated. The mean duration of use was estimated as follows: If " $i$ " and " $p$ " denotes the incidence and prevalence rates, then the estimate of mean duration of use ("d") is $d=p /(i \bullet(1-p))(27)$. This estimate is based on the assumption that the incidence rate is constant over time.

As this investigation only measures filled prescriptions and not real use of the drugs, we could not be sure what drug use pattern followed filling a prescription. Different patterns of actual use could lie behind apparently similar rates and lengths of use. This is especially true for persons with low mean average volumes of use and possibly also long duration. Such an individual could take the drug occasionally or take larger amounts at specific times.

\section{RESULTS}

\section{Number of users}

During the observation period, 513558 separate individuals filled at least one prescription for a benzodiazepine. The number of unique users filling prescriptions was around 61 per 1000 person-years. $65 \%$ of all users were female.

The cumulative number of incident users of benzodiazepines is shown in figure 1. In the beginning, many users who are registered for the first time in the database were not in fact incident users, but had filled their previous prescription before the start of our observation period. By plotting the cumulative number of incident users as in figure 1, we could estimate the actual incidence rate corresponding to when the curve increased at a constant rate. This happened after approximately 3 years. At that time point the incidence rate was approximately 15 per 1000 person-years (table 2).

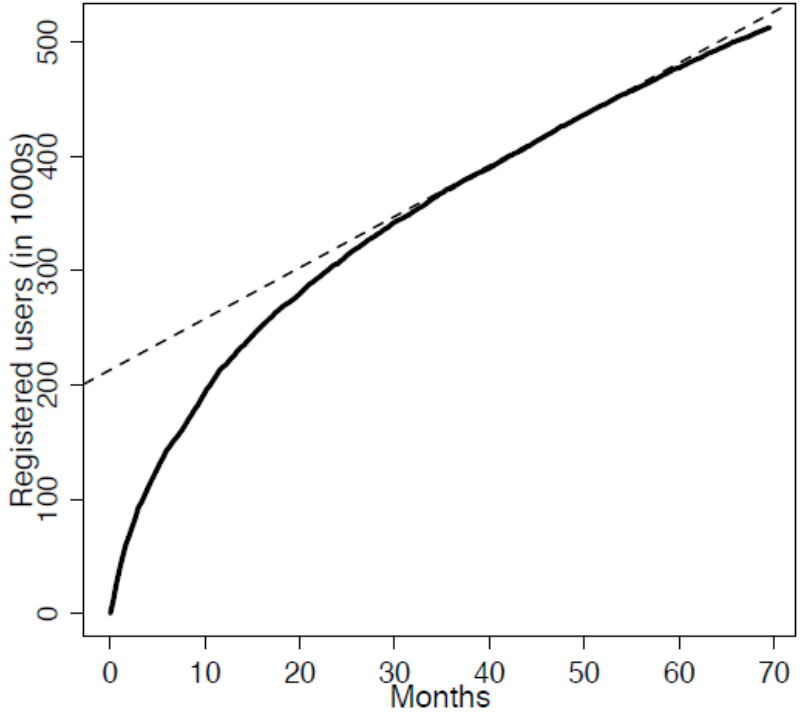

Figure 1. Cumulative incidence of prescriptions for benzodiazepines in Norway as registered in the Norwegian prescription database from January $1^{\text {st }} 2004$ and 5 years and 10 months onwards. Figures on $\mathrm{x}$-axis denote the number of days after start of observation. Figures on y-axis denote the number of first time registered users (in thousands).

This indicates that many patients fill prescriptions for benzodiazepines very seldom, some only once every third year. Extrapolating this straight line beyond the $\mathrm{y}$-axis indicates that approximately 195-200 000 patients were users of benzodiazepines, corresponding to a prevalence of 55 per 1000 , before the start of the observation period.

We also observed that the incidence rate fell at the end of the observation period. The rate fell from approximately 15 per 1000 person-years in 2007 to approximately 12 per 1000 person-years in 2009, or a fall of approximately $9-10 \%$ per year in incidence rate (table 2).

\section{Mean volume used}

The mean volume used could be calculated for all those who received at least two prescriptions during the observation period. The average mean volume used for all those who received at least two prescriptions was $0.3 \mathrm{DDD} /$ day. Figure 2 gives the rates of use for all users, incident users, and those initiating use prior to 2004. 


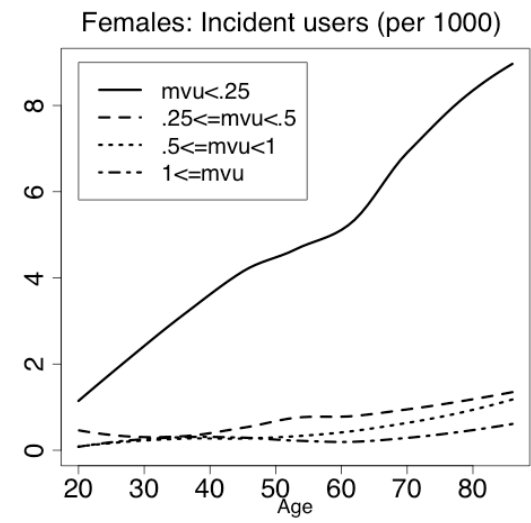

(c)

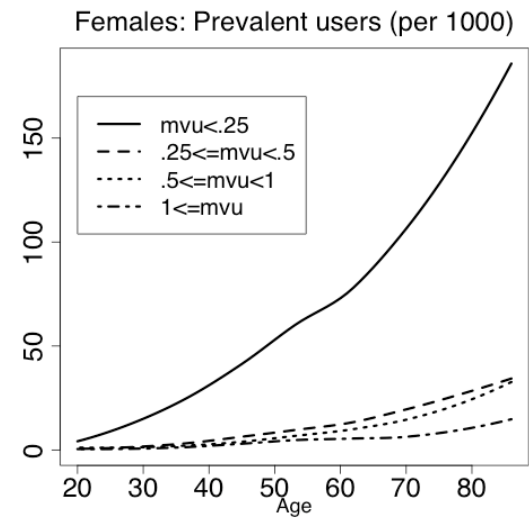

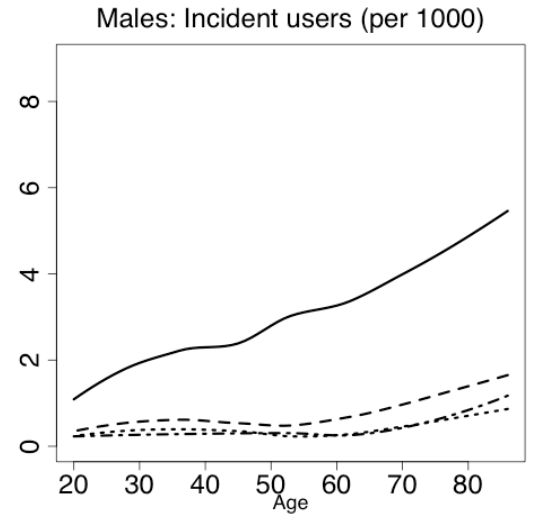

(d)

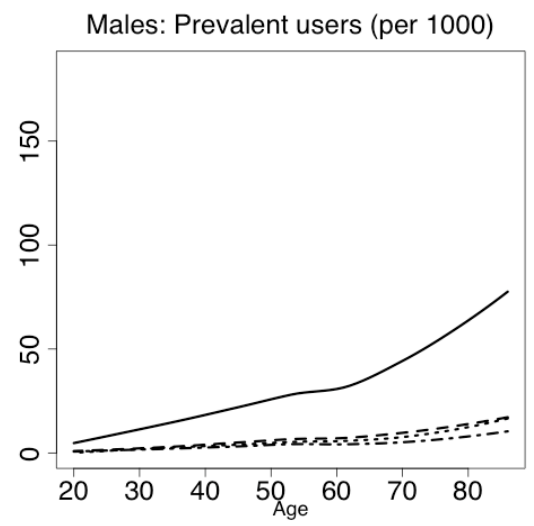

Figure 3. Rate of incident use ( $3 a$ and $b$ ) and prevalent use ( $3 c$ and d) of benzodiazepines according to gender and age, grouped according to mean volume used ( $\mathrm{mvu})$ in units of defined daily doses per day (DDD/day).

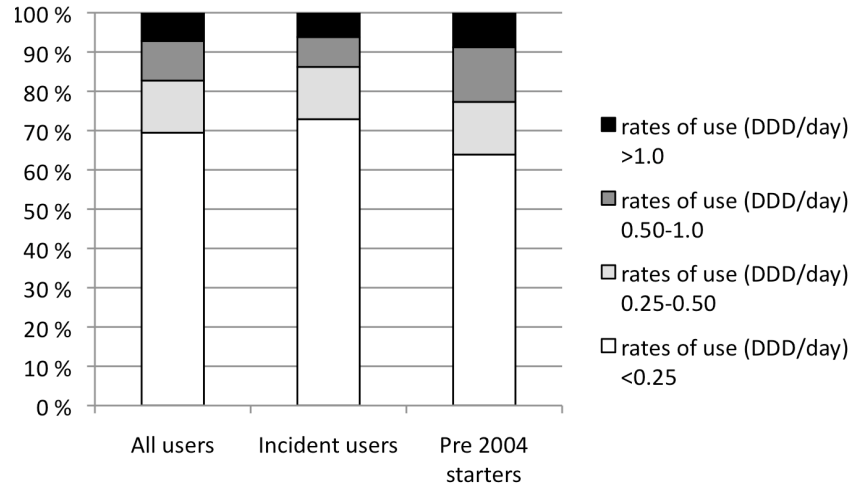

Figure 2. Fraction of all users, incident and "old" users divided according their mean volume used, indicating that incident users in the observation period use less than the users who started previously.

The average mean volume used among female users was $0.28 \mathrm{DDD} /$ day, while the average use among male users was $0.39 \mathrm{DDD} /$ day. The rate of users within groups with different mean volume used among male and female prevalent and incident users of different ages is given figure 3 . The figure illustrates that both incident use an prevalent use increases with age, but more so with lower mean volumes used and among females. The dosing was on average higher among males.

\section{Length of use}

The real length of use, which could be several years, was not possible to calculate with the observation period at hand. However, the estimated average length of use according to the mean volume used is given in table 3 . The average length is estimated to be between 9 and 15 years, with somewhat longer durations for the higher volume users. Table 3 indicates that higher volume users have a longer mean duration of use. There are also other signs that those who had started using benzodiazepines prior to January 2004 had used benzodiazepines for many years. Firstly, the average age of all benzodiazepine users was calculated to be 62 years of age, while the incident users had an average age of 57 years. Secondly, we must address the time needed to accumulate the number of prevalent users with the observed incidence rate. Of the 55000 incident users each year, 30000 will only fill one prescription, while 25000 will fill more than one. Approximately half of the users were prescribed benzodiazepines for more than 2 years. If the incident rate did not increase dra- 
Table 3. Mean duration of use by mean volume use. Using the traditional method (27).

\begin{tabular}{lcccc}
\hline Mean volume used (DDD/day) & $(<0.25)$ & $(0.25-0.50)$ & $(0.5-1.0)$ & $(>1.0)$ \\
Mean duration (in years) & 9.04 & 10.86 & 15.35 & 13.45 \\
\hline
\end{tabular}

matically during recent years (the opposite being more likely) most of the 200000 users from before 2004 must have used benzodiazepines for some time. It would take approximately 16 years (200000 users/ $(1 / 2 \cdot 25000$ users/year $)=16$ years $)$ to accumulate the number of prevalent users observed. With the observed possible decline in incidence rates (figure 1) this time period estimate could be shorter.

\section{Discussion}

In this study, we established that around 61 per 1000 Norwegians filled at least one prescription for benzodiazepines per year. The incidence rate was around 15 per 1000 person-years, but probably fell by as much as $10 \%$ per year. As found in earlier studies, more females than males were prescribed benzodiazepines $(16,17)$. The mean volume used was often very low and for the most part quite stable. Female patients used a lower mean volume than male patients. Few patients seemed to increase their mean volume used substantially. Approximately $50 \%$ of the users filled only one prescription or ended their use within a two year period. On the basis of this information only, this could be viewed as appropriate use within the guidelines and the recommendations from the drug manufacturers.

There were, however, signs that a substantial group used benzodiazepines for a much longer time. This long term use may be viewed as unfavorable because where there is use on a regular basis over longer periods of time and tolerance to the therapeutic effects may develop. The patients may experience only adverse effects (24), including sleeping and anxiety problems. The number of long term regular users may indicate that quite a few Norwegians will be in a situation where their sleeping and anxiety problems are in fact caused by the drugs meant to cure them. The drugs will, to a larger degree, be used to treat abstinence reactions than the disease that led to the prescribing in the first place. For such patients, there is a need to make serious efforts to manage for longer periods without the drug and to assess the situation in an abstinent phase. Also as people use the drugs for many years, starting in their late fifties or early sixties, they will grow older, to an age where they may have less cognitive residual capacity, and this will increase the problems of cognitive impairment following intake of benzodiazepines.

On the other hand, it is interesting that a majority of the long term users are prescribed very low quantities of the drug. Also the patients being prescribed higher doses are more likely to be short term users. As in other studies, we found males using higher doses for a shorter time and females being prescribed lower doses for a longer period of time (17). It is difficult to determine whether long term use of the drug in low doses is due to intermittent intake of larger doses or if the drug taking is spread evenly over time. The patients using these drugs over many years may have long lasting diseases and be taking the drugs intermittently to alleviate their symptoms. So what appears to be long term use in low daily doses may in fact be appropriate but intermittent use of larger doses for diseases with a fluctuating character, such as epilepsy, insomnia, anxiety or more major psychiatric disorders. This second scenario is supported by the fact that patients are not increasing their doses of benzodiazepines. Such dose escalations are often a hallmark of tolerance development and dependency. The findings of this study indicate that we should be careful not to assume that use, even very long term use, is necessarily harmful use or abuse. The term pseudo therapeutic long term use (25) is useful for a large group. There may also be a lesson to learn from these thousands of patients who apparently experience usefulness of benzodiazepines over prolonged periods of time, despite the warnings. There perhaps needs to be discussion at the level of individual patients whether this usage is problematic or not (26). Some patients may benefit from trying to curb their use of benzodiazepines, even at such a low level. And some may find it surprisingly easy to rid themselves of a bad habit $(25,26)$.

The incidence rate of benzodiazepine use seems to be falling quite substantially. The precise fall in incidence rate was difficult to calculate, but in our data suggested a fall of approximately $9-10 \%$ per year in incidence rate. This is of particular importance when observing that many patients, once started, continue using the drugs for many years. Knowing that approximately half of the patients stop their use after a shorter period of time, only future investigations will reveal if the lower incidence rates will lead to an actual decline in long term use. It may be that the fall in incident use is among those who would previously have used the drug for a shorter period of time. The decline in incidence could also be because patients are switching to other drugs, the hypnotics zopiclone and zolpidem being particularly relevant in Norway (27). A recent investigation did, however, reveal that a similar decline in incidence rate was found for these drugs (28). Our investigation also suggests the possibility that rates of use are lower among newer incident users. This is important because patients tend to stay on similar dosing over time, so the starting level is an important therapeutic point. Only future investigations 
with longer observation periods can reveal the true significance of this observation. However, the finding appears positive from a regulatory and drug safety point of view. It may indicate that years of warnings from regulatory authorities against the liberal use of benzodiazepines have borne fruit.

It must be added that our observed fall in incidence rates need to be confirmed in studies with a longer observation period. The 1 year and 9 months of observation time after the first year, from which it is possible to determine true incidence rate (2007) is too short a time period for reliable conclusions to be drawn. Our observation period is obviously also too short to give accurate estimates of length of use.

This investigation is based on data from a nationwide register, ensuring complete capture of all prescriptions filled at Norwegian pharmacies outside hospitals during the observation period. This prevents selection and recall bias. We do not know, however, if or how the dispensed drugs were taken. This lack of information has implications for the calculation of rates of use. Lastly, the NorPD does not record indications for use and contains limited clinical data. It is therefore difficult for us to determine the appropriateness of the prescribing and drug use. This also makes it difficult to determine whether a given use pattern represents harmful use, abuse or dependency. These are clinical diagnoses which are not possible to determine on the basis of dispensing data. We also have no information on other illegal drug use or alcohol used by the patients.

\section{ACKNOWLEDGEMENTS}

The authors would like to thank Elisabeth Eriksen at the Norwegian Prescription Database for her help in preparing the data for analysis. The work was financed by a grant from the Norwegian Directorate of Health to the Norwegian Institute of Public Health.

\section{REFERENCES}

1. Bramness JG, Skurtveit S, Mørland J. Clinical impairment of benzodiazepines - relation between benzodiazepine concentrations and impairment in apprehended drivers. Drug Alcohol Depend 2002; 68 (2): 131-41.

2. Neutel CI. Risk of traffic accident injury after a prescription for a benzodiazepine. Ann Epidemiol 1995; 5 (3): 239-44.

3. Neutel I. Benzodiazepine-related traffic accidents in young and elderly drivers. Hum Psychopharmacol 1998; 13: S115-23.

4. Engeland A, Skurtveit S, Mørland J. Risk of road traffic accidents associated with the prescription of drugs: a registry-based cohort study. Ann Epidemiol 2007; 17: 597-602.

5. Neutel CI. The epidemiology of long-term benzodiazepine use. Int Rev Psychiatry 2005; 17 (3): 189-97.

6. Foy A, O'Connell D, Henry D, Kelly J, Cocking S, Halliday J. Benzodiazepine use as a cause of cognitive impairment in elderly hospital inpatients. J Gerontol A Biol Sci Med Sci 1995; 50 (2): M99-106.

7. Paterniti S, Dufouil C, Alperovitch A. Long-term benzodiazepine use and cognitive decline in the elderly: the Epidemiology of Vascular Aging Study. J Clin Psychopharmacol 2002; 22 (3): 285-93.

8. Gladsjo JA, Rapaport MH, McKinney R, Auerbach M, Hahn T, Rabin A, et al. Absence of neuropsychologic deficits in patients receiving long-term treatment with alprazolam-XR for panic disorder. J Clin Psychopharmacol 2001; 21 (2): 131-8.

9. McAndrews M, Weiss R, Sandor P, Taylor A, Carlen P, Shapiro C. Cognitive effects of long-term benzodiazepine use in older adults. Hum Psychopharmacol 2003; 18: 51-7.

10. Komitéen for medisinsk teknologivurdering. Bruk av benzodiazepiner. Konsensuskonferanse. Rapport nr. 10. Oslo: Norges forskningsråd, 1996.

11. Mant A, Walsh RA. Reducing benzodiazepine use. Drug Alcohol Rev 1997; 16 (1): 77-84.

12. Chung KF, Cheung RC, Tam JW. Long-term benzodiazepine users - characteristics, views and effectiveness of benzodiazepine reduction information leaflet. Singapore Med $J$ 1999; 40 (3): 138-43.

13. Dollman WB, Leblanc VT, Stevens L, O'Connor P J, Roughead EE, Gilbert AL. Achieving a sustained reduction in benzodiazepine use through implementation of an area-wide multi-strategic approach. J Clin Pharm Ther 2005; 30 (5): 425-32.

14. Ten Wolde GB, Dijkstra A, van Empelen P, van den Hout W, Neven AK, Zitman F. Long-term effectiveness of computer-generated tailored patient education on benzodiazepines: a randomized controlled trial. Addiction 2008; 103 (4): 662-70.

15. Kornor H, Pedersen W, von Soest T, Rossow I, Bramness JG. [Use of benzodiazepines and cannabis in young adults]. Tidsskr Nor Laegeforen 2010; 130 (9): 928-31.

16. Kjosavik SR, Ruths S, Hunskaar S. Psychotropic drug use in the Norwegian general population in 2005: data from the Norwegian Prescription Database. Pharmacoepidemiol Drug Saf 2009; 18: 572-8.

17. Hartz I, Lundesgaard E, Tverdal A, Skurtveit S. Disability pension is associated with the use of benzodiazepines 20 years later: A prospective study. Scand J Public Health 2009; 37 (3): 320-6. 
18. Hartz I, Tverdal A, Skille E, Skurtveit S. Disability pension as predictor of later use of benzodiazepines among benzodiazepine users. Soc Sci Med 2010; 70 (6): 921-5.

19. van Hulten R, Isacson D, Bakker A, Leufkens HG. Comparing patterns of long-term benzodiazepine use between a Dutch and a Swedish community. Pharmacoepidemiol Drug Saf 2003; 12: 49-53.

20. Lagnaoui R, Depont F, Fourrier A, Adouelfath A, Bégaud B, Verdoux H, et al. Patterns and correlates of benzodiazepine use in the French general population. Eur J Clin Pharmacol 2004; 60: 523-9.

21. Skurtveit S, Furu K, Bramness J, Selmer R, Tverdal A. Benzodiazepines predict use of opioids - a follow-up study of 17,074 men and women. Pain Med 2010; 11 (6): 805-14.

22. Hallas J. Drug utilization statistics for individual-level pharmacy dispensing data. Pharmacoepidemiol Drug Saf 2005; 14: 455-63.

23. Hallas J, Støvring H. Templates for analysis of individual-level prescription data. Basic Clin Pharmacol Toxicol 2006; 98: 260-5.

24. Vgontzas AN, Kales A, Bixler EO. Benzodiazepine side effects: role of pharmacokinetics and pharmacodynamics. Pharmacology 1995; 51 (4): 205-23.

25. Griffiths RR, Weerts EM. Benzodiazepine self-administration in humans and laboratory animals - implications for problems of long-term use and abuse. Psychopharmacology 1997; 134: 1-37.

26. Cook JM, Marshall R, Masci C, Coyne JC. Physicians' perspectives on prescribing benzodiazepines for older adults: a qualitative study. J Gen Intern Med 2007; 22 (3): 303-7.

27. Mellingsæter T, Bramness JG, Slørdal L. Er z-hypnotika bedre og tryggere sovemedisiner enn benzodiazepiner? Tidsskr Nor Lageforen 2006; 126 (22): 2954-6.

28. Berg C, Sakshaug S, Handal M, Skurtveit S. Z-hypnotika - sovemidlene som dominerer markedet i Norge. Norsk Farmaceutisk Tidsskrift 2011 (4): 14-7. 